ESTUDIOS 



\title{
PROTECCIÓN DE LOS DERECHOS FUNDAMENTALES EN LA PANDEMIA DEL CORONAVIRUS
}

\author{
OLIVER LEPSIUS ${ }^{1}$ \\ Catedrático de Derecho Público y Teoría Constitucional \\ Universidad de Münster
}

TRC, n. ${ }^{\circ} 47,2021$, pp. 71-96

ISSN $1139-5583$

\begin{abstract}
SUMARIO
I. Protección de los derechos fundamentales en condiciones constitucionales ordinarias. II. La protección de los derechos fundamentales en el ordenamiento jurídico paralelo del coronavirus. III. Abolición del sistema legal paralelo.
\end{abstract}

De acuerdo con el art. 1.3 de la Ley Fundamental (en adelante, GG) los derechos fundamentales vinculan a los poderes legislativo, ejecutivo y judicial. La vinculación no solo representa su limitación. Si se reconocieran los derechos fundamentales simplemente por su efecto limitativo, entendiéndolos solo como derechos subjetivos de defensa ${ }^{2}$ se subestimaría la valoración y el significado de los derechos fundamentales al que hace referencia el art. 1.3 GG. En todo caso, el art. 1.3 GG no termina ahí, y de ser así no sería necesario garantizar la protección jurídica individual de forma fundamental mediante el art. 19.4 $\mathrm{GG}^{3}$. Desde el principio en la República Federal el ordenamiento jurídico se ha basado materialmente en los derechos fundamentales: el ordenamiento jurídico es legítimo no

1 Traducción de Janire Mimentza Martín, Profesora Adjunta de Derecho Constitucional en la Universidad del País Vasco. El texto original fue objeto de publicación en Recht und Politik, Jahrgang 56, Heft 3 (2020). Miembro del Grupo de Investigación «Constitucionalismo Multinivel y Derecho Comunitario» del Sistema Vasco IT 1380-19.

2 Los derechos de defensa (Abwehrrechte) o de carácter negativo limitan las injerencias del Estado a ciertas áreas de la vida humana (Nota del Traductor).

3 Art. 19.3 GG: Toda persona cuyos derechos sean vulnerados por el poder público, podrá recurrir a la vía judicial. Si no hubiese otra jurisdicción competente para conocer el recurso, la vía será la de los tribunales ordinarios. No queda afectado el artículo 10, apartado 2, frase 1, que indica que las restricciones sólo podrán ser ordenadas en virtud de una ley (Nota del Traductor). 
solo porque se creó mediante los procedimientos adecuados y por los órganos competentes, sino porque está arraigado en los valores de un orden de derechos fundamentales. En consecuencia, los derechos fundamentales tienen - que es una peculiaridad del orden constitucional alemán — una doble función: son derechos individuales de libertad ${ }^{4}$ y elementos objetivos del ordenamiento 5 . Desde 1958 la sentencia Lüth sirve como ejemplo de esta doble naturaleza ${ }^{6}$. La jurisprudencia del Tribunal Constitucional Federal (en adelante TCF) y la ciencia del Derecho Constitucional se han dedicado durante setenta años con esmero y creatividad al diseño de esta dualidad ${ }^{7}$.

Por lo tanto, la protección de los derechos fundamentales no es una vía de un solo sentido que comienza en el individuo, sino es la promesa de la Constitución que deben implementar todos los poderes públicos. El ordenamiento jurídico en su totalidad debe ser libre, no solo el estatus legal del individuo. Antes de poder abordar preguntas concretas sobre si la situación de los derechos fundamentales ha cambiado en tiempos de la pandemia del coronavirus, debemos primero analizar los efectos de los derechos fundamentales en el marco constitucional ordinario. Solo después, en un segundo paso, será posible analizar la realidad presente marcada por el coronavirus.

\section{PROTECCIÓN DE LOS DERECHOS FUNDAMENTALES EN CONDICIONES CONSTITUCIONALESORDINARIAS}

\section{Protección de los derechos fundamentales mediante leyes}

La Ley Fundamental respecto a la protección de los derechos fundamentales, hace referencia ante todo a la ley. La Constitución no entiende las leyes como base para la vulneración de libertades, sino también como medio de configuración de los derechos fundamentales. Cabe pensar en la propiedad, que normativamente no existiría sin leyes, y, por tanto, no tendría protección como derecho fundamental. Como regla general las áreas de protección de los derechos fundamentales son

4 Estas libertades fundamentales (Freibeitsrechte) son equiparables a los Derechos civiles (Nota del Traductor).

5 Vista general de las funciones, por ejemplo, en H. Dreier, Dimensionen der Grundrechte, 1993; ders., en: H. Dreier (ed.), GG-Kommentar, vol. 1, 3. edición 2013, Vorbem. Vor Art. I GG n. ${ }^{\circ}$ marg. 82-108; W. Kahl, en: O. Depenheuer/C. Grabenwarter (ed.), Verfassungstheorie, 2010, p. 24; H. D. JARASS, «Die Grundrechte: Abwehrrechte und objektive Grundsatznormen», en: P. BAdura/H. Dreier (ed.), FS 50 Jahre BVerfG, vol. I, 2001, pp. 35-53.

6 BVerfGE 7, 198 - Lüth [1958], vid. P. RAmAdori, Grundrechte als objektive Werte: Das Lüth-Urteil I), en: D. Grimm (ed.), Vorbereiter - Nachbereiter, 2020, pp. 39-71; H. SCHULZE-FiELITZ, «Das Lüth-Urteil - nach 50 Jahren», en: JURA 2008, pp. 52-57; T. HENNE/A. RIEDLINGER (ed.), Das Lüth-Urteil in (rechts-)historischer Sicht, 2005.

7 Sobre el reclamo de la constitución U. VolkmanN, Grundzüge einer Verfassungslehre der Bundesrepublik Deutschland, 2003, p. 3. 
configuradas por ley, o como se utiliza con frecuencia «influenciadas» decisivamente por las leyes. La ley tiene la función de apoyar que las libertades fundamentales tengan efecto en el ordenamiento jurídico. Esperamos que la ley esté del lado de los derechos fundamentales y obtenga resonancia en el Derecho ordinario. Cuando el Derecho ordinario está influenciado por los derechos fundamentales, aumenta el poder de eficacia de los estos respecto a la concepción de que los derechos fundamentales —al nivel del derecho constitucional- solo actúan como derechos de defensa. Para que los derechos fundamentales tengan efecto en el Derecho ordinario las leyes deben abordar conflictos entre derechos fundamentales, dado que la configuración de un derecho fundamental tiene efectos sobre otro. La configuración legal de los derechos fundamentales presupone la armonización de los conflictos de intereses. Los derechos se caracterizan por el hecho de que generan obligaciones en otra parte. Cuando las leyes configuran derechos fundamentales, también deben a su vez regular las obligaciones relacionadas que afectan a otras necesidades y bienes constitucionalmente protegidos. Por lo tanto, la ley que configura los derechos fundamentales debe abordar los conflictos entre los bienes jurídicos. Así, las leyes son el medio principal para armonizar los conflictos de derechos fundamentales. A menudo será una cuestión de perspectiva responder si existe una injerencia por parte de una ley a un derecho fundamental: lo que para una persona es una vulneración, desde la perspectiva de otra será una configuración.

La Constitución típicamente aborda esta doble función (configuración y armonización $)^{8}$ de la ley en los derechos fundamentales a través de la reserva de ley en los artículos de derechos fundamentales. La jurisprudencia y la doctrina han desarrollado — desde la perspectiva del derecho de organización del Estado — criterios adicionales que fundamentan y exigen la tarea de configuración y armonización de la ley ${ }^{9}$. Sobre todo, se debe de mencionarla doctrina del contenido esencial ${ }^{10}$. El poder legislativo debe regular lo esencial por sí mismo sin delegar en otros poderes, ni en el ejecutivo (habilitación para otorgar reglamentos) ni en el poder judicial (términos jurídicos indefinidos, cláusulas generales). El TCF definió lo esencial como lo relevante desde el punto de vista de los derechos fundamentales. En otras palabras: si el objeto de la regulación afecta a varios derechos fundamentales cuyas áreas de protección están en conflicto, se requiere una decisión legal fundamental sobre el conflicto. Dejar esta decisión a otros poderes reduciría el amplio impacto de los derechos fundamentales al que aspira la Ley Fundamental.

8 Traducido de los conceptos Ausgestaltung und Ausgleich que se repiten a lo largo de todo el texto (Nota del autor).

9 Visión general en O. LePsius, «Gesetz und Gesetzgebung», en: Handbuch des Verfassungsrechts, 2020, número de margen (en adelante n. ${ }^{\circ}$ marg. Nota del traductor) 46-68; F. REIMER, «Das Parlamentsgesetz als Steuerungsmittel und Kontrollmaßstab», en: W. Hoffmann-Riem/E. SchmidT-Assmann/A. Vosskuhle (ed.), Grundlagen des Verwaltungsrechts vol. I, 2 edición, 2012, § 9 B. II/III; H. SCHUlZE-FIELITZ, en: H. DreIER (ed.), GG-Kommentar, Vol. II, 3. ed. 2015, Art. 20 (Rechtsstaat) n. ${ }^{\circ}$ marg. 113 y ss. demás referencias.

10 Para conocer decisiones clave vid. BVerfGE 40,237 (250) - Strafvollzugsverordnung [1975]; BVerfGE 49, 89 (125) - Kalkar [1978]; 68, 1 (86) - Nachrüstung [1984]. 


\section{Protección de los derechos fundamentales mediante la legislación}

Estas funciones de contenido relativas a la protección de los derechos fundamentales a través de las leyes (configuración y armonización) están respaldadas por la organización y el proceso legislativo. La legislación es, ante todo, tarea de los parlamentos (Bundestag, parlamentos de los Länder) porque en ellos se vela por la armonización de intereses mediante la representación. El orden constitucional no reconoce otro órgano que represente mejor a la sociedad plural que un Parlamento. Por ello, este órgano, por su composición y legitimación es el más adecuado para articular y resolver a un nivel normativo general y abstracto las cuestiones en conflicto. La idea de la «reserva parlamentaria», que frecuentemente destaca la jurisprudencia de Karlsruhe ${ }^{11}$, muestra como las decisiones políticas importantes (ponderaciones) derivan a este órgano. En él encontramos las mejores condiciones organizativas para abordar desde un punto de vista normativo de los conflictos de derechos fundamentales. Además, el procedimiento parlamentario es el que mejor tiene en cuenta la configuración y la armonización: en los parlamentos se negocia y decide públicamente para que prevalezca la transparencia y puedan intervenir los controles de la sociedad civil. Los parlamentos deciden en base al principio mayoritario, dado que hay que formar mayorías; no existen prima facie, lo que inevitablemente llevará a compromisos. La voluntad de compromiso aumenta la probabilidad de poder influir en la decisión mayoritaria del órgano. La configuración y la armonización son las condiciones más favorables. Con los comités que no se reúnen en público, los parlamentos disponen de estructuras que sondean la indulgencia mutua y preparan compromisos. Y finalmente, la decisión parlamentaria es modificable sin que el parlamento pierda prestigio, mientras que otros poderes ante correcciones posteriores tienen el peligro de perder credibilidad o experiencia. El Parlamento es el único órgano que no se obliga institucionalmente mediante compromisos, y esa es otra condición favorable para la constante búsqueda del equilibrio entre la configuración y la armonización.

\section{Protección de los derechos fundamentales mediante la separación de poderes}

La separación de los poderes legislativo y ejecutivo promueve la protección de los derechos fundamentales, porque se debe hacer una separación institucional entre el nivel de creación general-abstracto de normas (derecho), con el de la

11 Las decisiones de referencia son BVerfGE 40, 237(249 f.)-Strafvollzugsverordnung [1975]; 83, 130 (142, 150)-Josefine Mutzenbacher [1990]; 108, 282 (312)-Kopftuch I [2003]; 147,253 (310)-Studienplatzvergabe Humanmedizin [2017]. 
generación de derecho individual específico (acto administrativo, sentencia). Con ello la misma norma (la ley) se legitima en dos situaciones normativas diferentes: por un lado, en el nivel de conflicto abstracto (igualación de intereses legales para un gran número de casos) y, por otro lado, en el nivel de aplicación específico (subsunción fáctica en casos individuales). Esta separación establece un valor específico añadido de libertad, que se expresará como concreción de la norma. En lo que respecta a la justificación de la ley los conflictos se trataran de manera diferente que en el nivel de la justificación de cada medida. Por medio de disposiciones legales se llega a diferentes acuerdos que, a través de actos individuales, porque en el primer caso están en juego preocupaciones sociales y en el segundo caso intereses individuales. Ambos niveles difieren en la intensidad de la intervención: por lo general, la ley en sí misma no vulnera derechos fundamentales (a menos que la ley excepcionalmente sea autoejecutable), pero para una injerencia requiere un acto de ejecución. Solo esto conduce de facto a la limitación de la libertad protegida. La limitación de la libertad con el acto ejecutivo presupone un caso específico. Los hechos, en cada caso, dirigen la subsunción de la ley general abstracta. La misma ley se puede justificar diferentes injerencias, porque las condiciones de aplicación de la ley pueden ser diversas. En otras palabras: la subsunción y la concreción de normas permiten además de tener en cuenta en cada caso las circunstancias del aumento de libertad - $\mathrm{O}$ también pérdida de libertad—, una búsqueda de equilibrio y estimación del efecto de derechos fundamentales.

\section{Protección de los derechos fundamentales mediante la jurisprudencia}

Solo cuando se han superado estas tres etapas de materialización y protección de los derechos fundamentales, entra en juego la protección jurídica ante los tribunales. Institucionalmente, los tribunales son órganos de protección jurídica individual, no de protección objetiva de los derechos fundamentales. No podrían brindar una protección tan amplia (solo deciden casos y lo hacen de manera retroactiva y previa solicitud). Un ordenamiento jurídico que para la protección de los derechos fundamentales únicamente confiara en los tribunales no sería libre. Porque cuántos derechos fundamentales se concretan cada día con fuerza de ley y que pocos son controlados judicialmente (y pueden y deben también ser controlados ante la escasez del recurso de jurisprudencia y la pérdida de tiempo de la jurisprudencia en la concreción de los derechos fundamentales). Por tanto, un ordenamiento basado en la libertad debe sistemáticamente garantizar de antemano la protección de los derechos fundamentales.

En Alemania, el control constitucional de TCF efectúa una protección objetiva de la libertad, que va más allá de la garantía de la protección jurídica subjetiva. El TCF sostiene que el recurso de inconstitucionalidad sirve al menos para 
el desarrollo objetivo del derecho constitucional ${ }^{12}$. También los procesos de control de normas están orientados hacia una ley objetiva. Es de destacar como un gran logro del Tribunal Constitucional Federal alemán el desarrollo de un control dinámico que opera a escala gradual, que sirve para la protección individual y sistémica de los derechos fundamentales: cuanto más intensa es la injerencia, mayores son los obstáculos para su justificación. Esto se debe principalmente al principio de proporcionalidad, que establece el estándar central de evaluación material ${ }^{13}$. Este principio cubre en el control judicial todas las garantías fundamentales arriba mencionadas: la doble funcionalidad de la ley en el nivel abstracto (injerencia y configuración), así como la relevancia de los hechos en el nivel de ejecución. Si se analiza la técnica de prueba de proporcionalidad con más detalle, encontramos que la proporcionalidad no permite una prueba abstracta, sino que aporta resultados más precisos cuando hay un acto de ejecución. La relación de propósito y medios presupone una referencia específica a la norma: entonces los objetos en conflicto pueden ser precisados y evaluados en la intensidad en la que son afectados. Sera entonces posible comprobar la idoneidad, necesidad y proporcionalidad de la medida elegida respecto al bien jurídico protegido. Sin los hechos no se podrá realizar una afirmación confiable sobre la idoneidad del medio, ni se podrá investigar si hubiera sido posible utilizar un medio más suave igual de adecuado para lograr el mismo objetivo (necesidad). También el elemento de la proporcionalidad se beneficia de una situación de conflicto concreto, porque será entonces cuando se favorezca un derecho fundamental de igual rango normativo frente a otro, dependiendo de la intensidad de los intereses protegidos ${ }^{14}$. Sería engañoso defender la idea de que aquí se ponderan los intereses protegidos. En el test de proporcionalidad no se ponderan los derechos fundamentales en sí, sino que se decide sobre la idoneidad de los escenarios de concreción. Esto se llama concordancia práctica (Konrad Hesse) o armonización moderada (Peter Lerche).

Todo esto aclara por qué el control de proporcionalidad encaja tan bien con el procedimiento de recurso de inconstitucionalidad. Se trata de limitaciones concretas en las libertades, que ya han sido plenamente resueltas las instancias de tribunales inferiores. Sin embargo, la estructura de la prueba también aclara por qué un control de ley (perspectiva del control de las normas, no del recurso de inconstitucionalidad) no funciona tan bien con el principio de proporcionalidad. Sin un acto de ejecución falta la concreción de la injerencia, lo que dificulta la

12 Más en Ch. Gusy, Die Verfassungsbeschwerde, en: P. Badura/H. Dreier (ed.), FS 50 Jahre $B \operatorname{VerfG}$, vol. I, 2001, 641-671.

13 Vid. B. Schlink, Der Grundsatz der Verhältnismäßigkeit, en: P. BAdura/H. Dreier (ed.), FS 50 Jahre BVerfG, vol. II, 2001, pp. 445-465; R. Poscher, «Verhältnismäßigkeit», en: Handbuch des Verfassungsrechts, 2020.

14 Cómo funciona el test de proporcionalidad en detalle O. Lepsius, «Chancen und Grenzen des Grundsatzes der Verhältnismäßigkeit», en: M. JestaedT/ders. (ed.), Verhältnismäßigkeit, 2015, p. 1 $(10-16)$. 
concreción de los bienes jurídicos en conflicto. Si se observa una ley en abstracto, solo se podrán hacer pronunciamientos hipotéticos sobre las injerencias. La intensidad de una injerencia puede ser estimada sin que se conozca su relevancia y gravedad real. Sin los hechos del caso en concreto, las pruebas de idoneidad y necesidad únicamente serán de carácter hipotético. Se trata del nivel general-abstracto de la ley, no de hechos subsumibles a un caso en concreto, sino de hechos generalizables y guías de conocimiento (hechos legislativos, como se dice en los EE.UU.). Estos hechos se pueden agregar o pronosticar estadísticamente, pero no se pueden probar. Esto conduce inevitablemente a un test de proporcionalidad estructurado de manera diferente con una intensidad de control limitado. Y finalmente, en el nivel del test de proporcionalidad en un control normativo abstracto de la ley, los bienes jurídicos a menudo no se pueden poner en una relación con sentido, porque la situación de conflicto sigue siendo demasiado abstracta, de modo es posible tomar decidir entre intereses protegidos de igual rango. Eso solo funcionaría si los objetos de protección ya estuvieran jerarquizados de manera abstracta, en el que uno se considerara más valioso que otro o que se le otorgara el valor más alto. Sin embargo, la Ley Fundamental no permite una jerarquización abstracta de los derechos fundamentales. Todos los derechos fundamentales de la Constitución son de igual rango normativo.

Como conclusión, se puede afirmar lo siguiente: la protección de los derechos fundamentales a través de la jurisprudencia funciona mejor contra actos concretos (constelación del recurso de inconstitucionalidad) que contra normas generales y abstractas (constelación de control normativo). Desde el punto de vista del Derecho de organización del Estado la conclusión es también correcta: según el art. 20.3 GG la vinculación legal del ejecutivo y el poder judicial es más intensa que el vínculo constitucional con el poder legislativo. Éste tiene una legitimación democrática directa, lo que debe llevar a su respeto mediante la jurisdicción constitucional. El hecho de que el poder legislativo acuerde según el principio de la mayoría significa también, que puede justificar sus decisiones en base a la mayoritaria; entonces básicamente no necesita razones objetivas. El principio de mayoría libera de justificaciones internas adicionales, porque la mayoría es mayoría. Las convicciones políticas de la mayoría prevalecen sobre razones objetivas controlables.

\section{Protección de los derechos fundamentales federal y de la sociedad civil}

Adicionalmente conviene hacer referencia a otras dos características estructurales de la protección de los derechos fundamentales: Los derechos fundamentales no están solo protegidos mediante órganos soberanos, sino ante todo por los ciudadanos. Porque los ciudadanos ejercen los derechos fundamentales y con ello los inspiran de vida. Sin un comportamiento libre nada podría protegerse desde el punto de vista de los derechos fundamentales. La jurisprudencia del TCF a la 
hora de determinar los ámbitos de protección de los derechos fundamentales da por supuesto este aspecto en el titular de los derechos fundamentales ${ }^{15}$. El TCF generalmente se niega a determinar autoritariamente las áreas de protección, y tampoco puede dar prioridad a ello a otros poderes soberanos. En la literatura jurídica este aspecto quedó plasmado con la aportación de la fórmula de Peter Häberle la «sociedad abierta de intérpretes constitucionales» ${ }^{16}$.

Finalmente, me gustaría destacar la función protectora y de libertad los derechos fundamentales del federalismo. En la República Federal de Alemania el sistema federal conlleva a que el nivel de ejecución, que es particularmente sensible a la libertad, no está centralizado, sino dividido entre 16 administraciones regionales. Por lo general, las leyes federales no se ejecutan por el gobierno federal, sino por otro titular. Al nivel más bajo administrativo a menudo ni siquiera es el Land, sino un municipio (en especial en Renania del Norte-Westfalia, donde el protagonismo de los municipios es la regla, y las autoridades administrativas del Land son la excepción). Solamente con la multiplicación de responsabilidades el federalismo de ejecución alemán mediante la separación de poderes horizontal logra aumentar la libertad, la independencia política y soluciones alternativas a la competencia de objetivos. El efecto de promover los derechos fundamentales del federalismo, puede, además, entrar en juego a nivel legislativo, porque la participación del Consejo Federal (Bundesrat) en la legislación federal fomenta la cultura de compromiso y armonización del sistema político.

\section{LA PROTECCIÓN DE LOS DERECHOS FUNDAMENTALES EN EL ORDENAMIENTO JURÍDICO PARALELO DEL CORONAVIRUS}

Como consecuencia del COVID-19, desde marzo de 2020, se ha creado en la República Federal de Alemania un sistema legal paralelo. Casi todos los comportamientos están ahora sujetas a una ley especial sobre protección contra infecciones, que materialmente consiste en Decretos. Según el\$32 de la Ley de protección contra infecciones ${ }^{17}$ (en adelante IfSG) son responsables los gobiernos de los Länder; en marzo de 2020 a través de la modificación del § 5 IfSG el Ministro Fede-

15 Vid. M. MORLOK, Selbstverständnis als Rechtskriterium, 1993.

16 P. HÄBERLE, «Die offene Gesellschaft der Verfassungsinterpreten», JZ 1975, 297 y ss.; vid. también P. HäBERLE, «Verfassungsgerichtsbarkeit in der offenen Gesellschaft», en: VAN OOYEN/MöLlERs (ed.), Handbuch Bundesverfassungsgericht im politischen System, 2. Edición, 2015, p. 31 y ss.

17 Infektionsschutzgesetz (IfSG) de 20 de julio de 2000 (Gaceta de Leyes Federales (en adelante BGB) I p. 1045), modificada por última vez el diciembre de 2020 (BGBl. I p. 3136). La Ley de Protección contra Infecciones (IfSG) es una ley federal contra las enfermedades transmisibles o peligrosas públicas en humanos y regula la cooperación y cooperación entre autoridades federales, estatales y locales, médicos, veterinarios, hospitales, instituciones científicas y demás involucradas. Debe prevenir las enfermedades transmisibles, detectar las infecciones a tiempo y prevenir su propagación (§ 1 IfSG) (Nota del Traductor). 
ral de Salud fue autorizado para emitir decretos especiales (organización hospitalaria, planificación de personal, control de entrada al país etc. ${ }^{18}$. Estos decretos que han influido en casi toda la vida pública han creado un orden legal paralelo. No se trata de derecho de excepción, ni de emergencia, porque no se derogará ninguna disposición de derecho vigente ${ }^{19}$. En base a la fuente del decreto no sería posible debido a la jerarquía de las normas ${ }^{20}$. No se trata de un estado de emergencia, ni un estado de excepción, sino un sistema legal paralelo. El cambio fundamental sobre el establecimiento del orden legal paralelo, se expresó de manera concisa en la página web del Ministerio de Salud y Cuidados de Baviera. Allí se podía leer con claridad: «En Baviera se ha declarado el estado de catástrofe. Los decretos legislativos, las disposiciones generales y las notificaciones del Gobierno del Estado de Baviera regulan la vida pública y privada» ${ }^{21}$.

Con el sistema legal paralelo existen injerencias en casi todos los derechos fundamentales. Con fines preventivos, se utilizan medios represivos, por lo que se llega a vulnerar un amplio número de libertades, que por su volumen y extensión no será explicado aquí ${ }^{22}$. Solo se respeta la libertad de expresión (Art. $5.1 \mathrm{GG}$ ) y la libertad de comunicación (Art. $10 \mathrm{GG}$ ), porque permiten comportamientos expresados digitalmente que son irrelevantes desde la perspectiva del derecho epidémico. Sin embargo, el resto de intereses fundamentales protegidos están cubiertos y regulados por el nuevo derecho originado por el coronavirus. Esto ha dado lugar a un sistema jurídico que en febrero de 2020 nadie hubiera imaginado: el uso efectivo de la libertad en todos los ámbitos ahora depende de decretos legislativos. Esto de ninguna manera corresponde al orden constitucional ordinario de protección de derechos fundamentales que acabo de describir. Las desviaciones se analizan con más detalle en la siguiente sección. Por lo tanto, compararemos las manifestaciones y estructuras de toma de decisiones del Estado constitucional ordinario con el sistema legal paralelo sobre el coronavirus.

18 Modificación de ley de 27.3.2020, BGB. I S. 587. Valoración crítica a la habilitación del Ministerio Federal de Salud a través de la ley para reformar el IfSG por Ch. MöLlers, Parlamentarische Selbstentmächtigung im Zeichen des Virus, en: www.verfassungsblog.de v. 26.3.2020; Ch. Möllers/F. Meine, « Eine Pandemie ist kein Krieg », F.A.Z. de 20.3.2020; A. KLAJKI, Neue Rechtsgrundlagen im Kampf gegen COVID-19, en: www. verfassungsblog. de 19.03.2020.

19 Para la conceptualización constitucional vid. Anna-Bettina Kaiser, Ausnahmeverfas-sungsrecht, 2020; als verwaltungsrechtliche Regelung siehe Tristan Barczak, Der nervöse Staat, 2020.

20 Esto se intentó en Baviera cuando la segunda vuelta en las elecciones municipales del 29 de marzo de 2020 se quiso imponer el voto por correo mediante decreto. Sin embargo, el parlamento del estado de Baviera luego cambió la ley electoral municipal y de distrito a tiempo. Vid. Lo que se discutió A. GIETF/F. $\mathrm{MiCH}$, Anordnung der Briefwabl verfassungswidrig, www.lto.de de 20.3.2020

$21 \mathrm{Vid}$. https://www.stmgp.bayern.de/coronavirus (23.4.2020). El estado de emergencia de 16.3. 2020 se terminó el 16.6.2020.

22 Vid. los primeros posicionamientos, A. Edenharter, Freiheitsrechte ade?, en: www.verfassungsblog.de de 19.3.2020; T. KIngreen, Whatever it Takes?, en: www.ver-fassungsblog.de de 20.3.2020; U. Volkmann, Der Ausnabmezustand, in: www.verfassungs-blog.de de 20.3.2020; O. Lepsius, Vom Niedergang grundrechtlicher Denkkategorien in der Corona-Pandemie, en: www.verfassungsblog.de de 6.4.2020 


\section{Insuficientes decisiones abstractas-generales}

A diferencia de una ley parlamentaria, el decreto legislativo no es fuente de derecho de configuración o de armonización, y mucho menos de compromiso. Los decretos legislativos debido a sus características fundamentales no están destinados, ni son adecuados para la protección de los derechos fundamentales. De un decreto legislativo se espera una contribución de normas diferente a la de la ley. En el Estado de derecho ambas fuentes del derecho no deben ser intercambiables, sino deben funcionar sobre la base de una división del trabajo ${ }^{23}$. La ley no debe sobrecargarse, por lo tanto el decreto legislativo no debe regular más que lo esencial. De ella esperamos regulaciones detalladas, el seguimiento de la ley, la transferencia de programas de regulación a programas de cumplimiento específicos y exactos $^{24}$. En consecuencia, la armonización de los derechos fundamentales en conflicto no debe, ni puede ser tarea de decretos legislativos, sino que debe lograrse por ley. El decreto traza y diseña el programa normativo en el marco de las obligaciones legales, pero no sustituye a la ley. El artículo 80, párrafo I, frase 2 GG expresa la competencia y forma jurídica de la reserva legislativa: en cuanto el legislador delega en el gobierno programas normativos, la ley debe determinar el contenido, objeto y alcance de la habilitación otorgada.

La determinación de los límites de delegación del art. 80.I.2 GG en casos individuales es difícil, porque el legislador mediante una delegación puede perseguir varios propósitos: a veces solo querrá delegar implementaciones técnicas, o permitir cláusulas experimentales, o aliviarse de excepciones o causas de fuerza mayor, a veces quieren permitir ajustes rápidos, o permitir estructuras regulatorias procesales o normas finales ${ }^{25}$ que procesal con menos obligaciones legales con un mayor nivel de participación, que debe evaluarse encada situación —en resumidas cuentas: la motivación del legislador parlamentario para la delegación el decreto legislativo al gobierno en términos de regulación y política son muy diversos. Sin embargo, el perfil de requisitos del decreto legislativo depende siempre de la motivación parlamentaria y su programación legal. No deben existir decretos que substituyan a la ley, ese es el mensaje clave del art. 80.I.2GG: el Consejo Parlamentario reaccionó a la práctica en la República de Weimar, en la que no existía una disposición comparable, que propició el empoderamiento del Reichstag ${ }^{26}$. La interpretación del art. 80 GG respeta la voluntad de configuración legal del legislador, pero no le permite «cheques en blanco», deshacerse de cuestiones o evitar

23 En más detalle M. Jestaedt, «Maßstäbe des Verwaltungshandelns», en: D. EhLERs/H. Pünder (ed.), Allgemeines Verwaltungsrecht, 15. edición. 2016, § 11 n. ${ }^{\circ}$ marg. 5 y ss.; M. MöstL, Exekutive Normsetzung kraft Delegation, en: ebd., § 20 n. ${ }^{\circ}$ marg. 1-4.

24 Lo fundamental en J. Saurer, Die Funktionen der Rechtsverordnung, 2005.

25 Vid. H. Bauer, en: H. Dreier (ed.), Grundgesetz Kommentar, vol. II, 3. edición. 2015, art. 80 n. ${ }^{\circ}$ marg. 37.

26 El contraste a través de la práctica en Weimar se hace evidente en C. Gusy, 100 Jahre Weimarer Verfassung, 2018; C Gusy, Die Weimarer Reichsverfassung, 1997, p. 162 y ss. 
ponderar y armonizar conflictos a través de la delegación. Como consecuencia, el alcance del decreto depende fundamentalmente de la decisión legislativa en la que el legislador debe respetar los límites de delegación del art. 80.I.2 GG, y también debe cumplir con la reserva de ley, en especial debe de cumplir con la forma de la doctrina esencial de la reserva parlamentaria. El legislador no debe perder de vista la configuración y la armonización de los intereses jurídicos en conflicto: este es un requisito de la jerarquía normativa, distinción del Estado de derecho, la legitimación democrática, el procedimiento normativo y es también expresión de las capacidades normativas de las diversas fuentes jurídicas de la ley o del decreto. Estos estándares constitucionales no se ajustan al sistema legal paralelo de los decretos sobre Coronavirus, porque la prolongación al nivel de decretos no cumple con la expectativa de la jerarquía de las normas, que exige que las cuestiones esenciales de los derechos fundamentales se traten mediante ley. Para expresarlo claramente, el nivel de regulación del decreto no se encuentra al mismo nivel de objeto de regulación que los derechos fundamentales.

El legislador con la estructura de delegación de $\S \S 32,28$ IfSG no quiso crear un sistema legal paralelo a nivel de decretos. Se trataba sobre el derecho de epidemias clásico, es decir, la preocupación sobre brotes y la lucha contra enfermedades infecciosas, que son medidas que se implantan en locales en específicos lugares peligrosos y van dirigidas contra personas individuales («perturbador»). El IfSG creó la base de la habilitación para prevenir enfermedades transmisibles en los seres humanos, detectar infecciones tempranamente y prevenir su propagación(§ 1 IfSG). La ley tiene principalmente fines preventivos, lo que significa, que el legislador está menos inclinado a llevar a cabo una ponderación sobre los bienes jurídicos protegidos al nivel abstracto y general, como en el caso de la persecución de objetivos represiva.

La habilitación de las medidas concretas( $§ 28$ IfSG) permite intromisiones en los derechos fundamentales, de libertad de la persona, la libertad de reunión, la libertad de circulación en territorio federal y el la vivienda, es decir, expulsiones y prohibiciones de entrada, prohibiciones de salida de ciertos lugares, limitar o prohibir eventos y reuniones de personas o como prohibir y cerrar ciertas instalaciones comunitarias que suelen ser el foco de propagación (piscinas, guarderías, escuelas, ver § 33 IfSG). Las restricciones a la libertad de circulación y la inviolabilidad del domicilio en términos de la ley de protección contra infecciones están cubiertas por las reservas de ley cualificadas en los artículos 11.II GG y 13.VIIGG. La protección de la libertad de circulación, al igual que la protección de la vida y la salud están sujetas a la reserva de ley del art. 2.II.3GG. Las injerencias en la libertad de reunión son problemáticas debido al efecto bloqueo (art. 8 II GG) de la Ley de reuniones frente al resto de derechos de defensa de peligros ${ }^{27}$.

27 Art: 8.2 GG: Para las reuniones en lugares abiertos, este derecho puede ser restringido por ley o en virtud de una ley (Nota del Traductor). 
Sin embargo, el IfSG no asume injerencias en la libertad religiosa o en los derechos económicos fundamentales; bajo la ley de protección contra infecciones ni siquiera ha tenido lugar una ponderación legal de estos bienes jurídicos protegidos: los hechos no coinciden con estos derechos fundamentales. Sin embargo, en la IfSG, basados en los decretos legislativos se realizaron prohibiciones en sectores completos de la industria, que en el contexto del confinamiento se evaluaron como «no relevantes para el sistema». La habilitación del decreto no cubre esas injerencias ${ }^{28}$. Desde un punto de vista material las prohibiciones a la industria no pueden basarse en el§ 28.I IfSG. La norma enlaza con prohibiciones de entrada a un local («ciertos lugares, lugares públicos»), pero no se refiere a sectores de industrias. La prohibición de entrada se justifica por el peligro del lugar. Sin embargo, las prohibiciones de estas industrias y servicios no trataban del cierre de negocios peligrosos, sino de restricciones de contacto entre personas. Para ello el medio utilizado es el cierre del local, que en ocasiones es desproporcionado e inadecuado (¿Qué contacto infeccioso peligroso se produce en librerías o floristerías) ${ }^{29}$. Una medida local de higiene más suave para la aplicación la restricción de contacto hubiera sido la restricción del aforo según el tamaño del local (requisito de mascarilla, etc.). Independientemente de la incertidumbre cambiante del riesgo de contagio el cierre de la construcción fue desproporcionado. En base a la ley de protección contra infecciones los autores del decreto seleccionaron un criterio inadecuado para el cierre de sectores industriales, porque no había indicios de que ciertos establecimientos tuvieran un mayor riesgo de infección que otros. El motivo principal del cierre no fueron las circunstancias del local, que influye en los contactos entre clientes, sino la valoración como empresa de servicios «no relevante para el sistema». Sin embargo, este criterio abstracto es una diferenciación inconstitucional, porque contiene un juicio de valor sobre la libertad de profesión, y distingue entre profesiones valiosas y profesiones «sin importancia». Lo que en sentido abstracto viola la igualdad de rango normativo de las áreas de protección de los derechos fundamentales entre sí y las profesiones entre sí, en particular.

El IfSG se basa en epidemias conocidas, no está hecho para una nueva enfermedad. Por lo tanto, hace frente a los conflictos de derechos fundamentales mediante la idea fundamental de aislar el proceso de infección, y no a través de un escenario a nivel nacional de reclamos contra personas cuyo comportamiento es per se inofensivo (denominado «no perturbador»).La referencia a los no perturbadores es básicamente una excepción puntual, cuando ante los actuales peligros otras medidas no prometen el éxito y las personas pueden reclamar «obligaciones

28 También expresa preocupación BVerfG, 1. Cámara del 1. Senado, decisión de 17.4.2020-1 BvQ37/ 20 n. ${ }^{\circ}$ marg. 37.

29 Hago referencia a estos ejemplos porque procedieron de manera diferente en los Länder. Las librerías permanecieron abiertas en Berlín y las floristerías en Hesse. En la mayoría de los Estados, sin embargo, ambos se mantuvieron cerrados. 
de nivel superior» sin dañarse o ponerse en peligro ${ }^{30}$. Incluso en relación los derechos fundamentales que el legislador pensó limitar al promulgar el IfSG, surge la pregunta adicional sobre el alcance y la intensidad de la injerencia de la delegación. La habilitación para emitir decretos no debe tener el efecto de una cláusula general, porque de lo contrario viola la reserva de la ley y los estándares de la doctrina de lo esencial y la reserva del parlamento.

En otras palabras: La ponderación del legislador en situaciones de colisión de derechos fundamentales (salud pública y libertades fundamentales) solo se realiza por el IfSG parcialmente. El legislador no contempló el peligro de enfermedades completamente nuevas con procesos infecciosos poco claros y sin experiencia terapéutica. Por eso pensó en catálogos de medidas epidemiológicas convencionales (aislamiento del suceso), pero no pensó en la regulación integral del comportamiento social o un confinamiento de prevención virológica. Por eso, consideró no restringir ciertos derechos fundamentales (libertad de profesión y propiedad, práctica religiosa). Eso significa: el fundamento de la habilitación es insuficiente para las medidas tomadas en base al decreto.

\section{Toma de decisiones al emitir el decreto}

Cuando la ley deja de ser una instancia de configuración y armonización, es entonces, en el proceso de emisión del decreto, cuando la ponderación abstracta y general debe proteger los derechos fundamentales. Sin embargo, cuando se emite el decreto se eliminan en gran medida la organización y los procedimientos para la protección de los derechos fundamentales. En los decretos gubernamentales no existe un órgano compuesto plural que actúe con el gobierno (del Land). Los gobiernos no están compuestos de manera plural, sino que para el nombramiento siguen criterios profesionales y políticos. Los gobiernos se organizan según el principio departamental, no según los intereses sociales o de bienes jurídicos fundamentales a proteger, y están sujetos al liderazgo político del jefe de gobierno. Aunque los gobiernos son órganos colegiados y se aplica a los votos el principio de mayoría, políticamente prevalece el jefe de gobierno. En un procedimiento de promulgación de este tipo, los derechos fundamentales solo se protegen en una medida muy limitada, debido a que cada sección se ocupa de sus respectivas áreas políticas e internamente solo tienen competencia para ellas. Por lo tanto, los Ministerios entienden los derechos fundamentales desde la perspectiva normativa de su área de responsabilidad, y no desde la perspectiva de armonizarlos intereses en conflicto. Generalmente el Ministerio de Justicia es responsable del área general de la protección de los derechos fundamentales, pero a su vez no tiene el

30 Ver, por ejemplo, § 19 OBG NW y las regulaciones comparables sobre el uso de no perturbadores en las leyes policiales federales y de los Länder. 
conocimiento de hecho del ámbito normativo al que se extienden las medidas, por lo que la intensidad de los intereses afectados y la proporcionalidad de los medios no podrán ser investigados y gestionados en su área de responsabilidad. La protección de los derechos fundamentales se desmenuza en el reparto de responsabilidades entre los Ministerios. Depende de una buena coordinación entre departamentos o de la formación de una voluntad y la toma de decisiones comunes en la totalidad del gobierno regional, donde los departamentos cubren todas las áreas políticas. La práctica nos demuestra, que tal organización y procedimiento protejan los derechos fundamentales es más una cuestión de azar, y del compromiso personal del Ministro o Primer Ministro.

En cuanto un Ministro emite un decreto legislativo ${ }^{31}$ el procedimiento de emisión será responsabilidad del Ministerio. Las consideraciones sobre los intereses de los derechos fundamentales se reducen aún más. Por razones de competencias durante el proceso de toma de decisiones Ministerial, no será posible considerar sistemáticamente las cuestiones de derechos fundamentales, y, sobre todo, no se armonizarán. Para esta actividad los Ministerios simplemente carecen de la experiencia adecuada. Si un Ministro de salud emite un decreto de protección contra infecciones, por ejemplo, la cultura o la economía no se considerarán interesantes, porque al no ser parte del área de responsabilidad del Ministerio de Salud ningún departamento se sentirá responsable de su coordinación. En el caso del decreto ministerial falta la posibilidad de introducir otros asuntos a través de una reunión de gabinete; procedimentalmente se limita alas posibilidades de acuerdos departamentales. Una vez más, no se debe subestimar la influencia personal del jefe de gobierno, ya que con medios políticos de control puede influir en un decreto ministerial, lo que los demás Ministros no pueden hacer. En el caso de los decretos ministeriales, la influencia del jefe de gobierno será aún mayor que en el de los decretos gubernamentales, dado que tiene que vencer menos resistencias departamentales.

Para las políticas del coronavirus, y para la configuración de las injerencias son de suma importancia las cuestiones de responsabilidad y organización dentro del gobierno. Puesto que el proceso de toma de decisiones y formación de voluntades en el gobierno sigue criterios completamente diferentes que el Parlamento. No es público. No sirve para la reflexión. En el gobierno no participa ningún grupo representativo de personas. La decisión está sujeta a jerarquías políticas. Que la

31 Según el art. 80.I.1 GG el Bundestag puede habilitar a nivel federal a un Ministro federal o al gobierno federal. El Canciller Federal no puede ser habilitado. A nivel del Land solo puede ser habilitado el gobierno regional. Sin embargo, según el art. 80.I.4 GG la ley delegada puede habilitar al gobierno regionalmediante undecreto legislativo a transferir la habilitación a otro organismo, por ejemplo, un Ministro de un Land. Esto lo permite el $\S 32.2$ IfSG, de modo que a nivel del Land ni siquiera los miembros del gobierno, sino también las autoridades (de salud) podrían emitir el decreto. Los Länder han regulado de manera diferente las responsabilidades para emitir los decretos legislativos de protección contra infecciones: en algunos Estados se emiten decretos gubernamentales (por ejemplo, Hesse), en otros decretos ministeriales (por ejemplo, Baden-Württemberg, Baviera, Renania del Norte-Westfalia). 
protección de los derechos fundamentales se convierta en una cuestión a regular será una cuestión incidental, no un mandato estructural. En resumen: en lugar de ponderar objetos de igual rango, hay una jerarquización política de los objetivos y con ellos los bienes a proteger; después de todo, también en la política también se establecen prioridades. Las tareas del gobierno y su distribución de competencias no están diseñadas para proteger derechos fundamentales. Además, si el jefe de gobierno se aventura mucho en público («es una cuestión de vida o muerte». «Cada muerte es una de más»), como hemos experimentado durante semanas, el proceso de toma de decisiones en el gobierno estará limitado políticamente. La jerarquía política de los intereses protegidos impide el equilibrio interno de áreas protegidas en conflicto. Tal jerarquía de intereses protegidos se refuerza cuando los expertos externos son parciales, y su tarea se refieren a un interés individual protegido. En otras palabras: cuando la toma de decisiones políticas dependa de la evaluación de riesgos del Instituto Robert $\mathrm{Koch}^{32}$ (en adelante RKI)o de los «virólogos domésticos» locales, será aún menos probable que se identifiquen los derechos fundamentales en conflicto, y mucho menos se armonicen. No se trata de un reproche a los expertos. Su tarea no va dirigida al conjunto de problemas de la sociedad, sino más bien los aspectos específicos y particulares en la que tienen experiencia. No se debe esperar que los expertos tengan en cuenta los derechos fundamentales, porque esto sobrepasaría su experiencia. La evaluación de riesgos del IRKno es adecuada como criterio rector para ponderar los derechos fundamentales protegidos, dado que el RKI solo sirve para proteger la salud. El RKI es un organismo subordinado al Ministerio Federal de Salud, que tiene como objeto la protección de la salud ${ }^{33}$. De hecho, es un departamento especializado independiente del Ministerio ${ }^{34}$. El RKI no es responsable de cotejar derechos fundamentales. No puede, ni debe, ni quiere abordar los conflictos de derechos fundamentales.

Además, si en un proceso de formación de voluntades y toma de decisiones todo se junta (decreto ministerial, jerarquización política de los objetivos por

32 El Instituto Robert Koch (abreviado RKI) es una agencia del gobierno federal alemán e instituto de investigación responsable del control y prevención de enfermedades. Como agencia federal superior, está subordinada al Ministerio Federal de Salud. El instituto fue fundado en 1891 y lleva el nombre de su director fundador, creador de la bacteriología moderna y premio Nobel, Robert Koch. El RKI continuamente registra la situación actual del COVID-19, evalúa toda la información y el riesgo para la población alemana. Además, el RKI da recomendaciones al público especializado y proporciona una descripción general de sus propios proyectos de investigación.

33 Vid. en el § 4 IfSG el apartado sobre tareas de Instituto Robert Koch (RKI). La disposición detalladamente trata sobre un bien protegido: la salud, en parte relacionado con el sistema de salud, que también incluye otros intereses de protección (práctica de la profesión de médico, funcionamiento de hospitales, compañías de seguros de salud). El RKI también es responsable de la salud de los animales, por lo que no persigue objetivos exclusivamente humanos. Por tanto, la experiencia sobre pronósticos y la elección de medios del RKI se basan en epidemias de animales.

34 Hasta 1994 las tareas las realizaba la Oficina Federal de Salud de Berlín. Se disolvió tras un escándalo relacionado con preparados de sangre contaminados con VIH; las tareas se repartieron entre tres institutos sucesores. 
parte del jefe de gobierno, experiencia unilateral), será de esperar que el resultado en la configuración del Decreto no pueda servir a los derechos fundamentales. Sin embargo, esta declaración no es una crítica. Los órganos actúan como se supone que deben actuar en función de sus responsabilidades. El gobierno funciona como se supone que debe funcionar. El problema principal radica en el fracaso de la programación de derechos fundamentales a nivel legal. Lo que no haya sido configurado y armonizado hasta aquí, ya no podrá ser compensado con medios normativos inferiores a la ley.

\section{Eludir la separación de poderes}

Al concentrar la regulación material al nivel de decretos, se elude la protección de los derechos fundamentales mediante la separación de poderes; la diferencia estructural entre la legislación general-abstracta (elaboración de leyes), y la elaboración de leyes específicas para individuos (ejecución). Muchas de las medidas de los decretos legislativos sobre la pandemia son autoejecutables. Es decir, no autorizan a las autoridades de ejecución a subsumir actos administrativos —en los que mediante hechos arbitrariosdel caso concreto se pueden tener en cuenta los derechos fundamentales-, pero sí contienen la norma a nivel general-abstracto.

En muchos decretos los servicios de culto han sido prohibidos sin excepción (fue diferente en Renania del Norte-Westfalia donde se exigió responsabilidad a la comunidad religiosa). Fundamentalmente, se prohibieron las reuniones, pero los decretos generalmente contenían excepciones (prohibición preventiva con reserva de autorización). Sin embargo, las autoridades administrativas inferiores (municipios y distritos) no hicieron ninguna excepción, incluso cuando el decreto lo permitía, y no existía ningún reparo relativo al derecho de protección de infecciones por parte de las autoridades sanitarias. En la práctica, como las autoridades locales no hicieron excepciones la prohibición de reunirse tuvo efectos en el ciudadano. Lo mismo ocurrió con las prohibiciones a la explotación de servicios y empresas. La prohibición del decreto se extendió a cada caso concreto. Las restricciones de contacto y las prohibiciones a la salida fueron punibles como infracciones administrativas. Las infracciones, hasta donde uno puede juzgar, se denunciaron. La prensa informó sobre el fetichismo normativo de los agentes responsables de la ejecución, se ensañaron denunciando incluso hechos que no tenían riesgo de infección, independientemente de la situación y del telos de la norma. La prohibición de sentarse en los bancos de los parques bávaros es un pars pro toto para la práctica de este tipo de ejecuciones ${ }^{35}$. Al no realizarse el examen

35 En relación a la ejecución del decreto sobre corona el 8 de julio de 2020 el Ministro de Salud y Atención del Estado de Baviera y en respuesta a una consulta por escrito de MdL Margit Wild comunicó lo siguiente: anunció que del 27.3.2020 al 18.5.2020 se registraron en Baviera 34.445 infracciones administrativas y se emitieron 16.006 multas, las que recibieron 1.503 objeciones, lo que motivó el retiro en 330 casos. 
de cada caso, se eliminó el nivel de concreción de la norma en el que a los derechos fundamentales en conflicto se le dar respuesta individual efectiva mediante la proporcionalidad.

\section{Protección jurídica sumaria urgente}

En última instancia, para la protección jurídica de los derechos fundamentales nos queda acudir al amparo de los tribunales. Lo que ocurrió con frecuencia, aunque teniendo en cuenta la extensión total de las medidas se esperaba mayor resistencia por parte de la población. La Asociación Alemana de Jueces informó el 8 de mayo de 2020 sobre la existencia de alrededor de 1000 solicitudes urgentes contra las restricciones derivadas del coronavirus. Desde el punto de vista social no es de un número elevado, pero sí a la luz de las capacidades de los tribunales administrativos. Además, representa un problema de base para el Estado de derecho, cuando el ejercicio de las libertades fundamentales en la práctica depende de una demanda judicial urgente. En este caso, el Estado de derecho no «funciona, porque si aunque trabajen duro», no es competencia de los tribunales posibilitar las libertades fundamentales, sino protegerlos individualmente.

El proceso judicial contra las medidas del Coronavirus tiene sus particularidades. Dado que a menudo a falta del acto administrativo, porque no llegaba la orden de ejecución (injerencia mediante el decreto, no del acto administrativo), los ciudadanos tenían que proceder directamente contra los decretos. § 47 I 2 VwGO permite en virtud del derecho del Estado particular solicitar el control de normas contra decretos legislativos del Land. Esto es posible en todos los Länder excepto en Berlín y Hamburgo. La solicitud de control de normas por parte del ciudadano es una característica especial del sistema de protección legal alemán, porque con él se puede perseguir un fin de protección de derecho objetivo, de lo contrario se debe de invocar una vulneración subjetiva del derecho (legitimidad para interponer una demanda $)^{36}$. El $\S 47$ I 2 VwGO tiene ahora en la práctica una relevancia de protección jurídica que nadie habría esperado con anterioridad. Así,

\footnotetext{
Alrededor de 15.700 avisos estaban relacionados con la salida del apartamento sin una razón válida. Hay que tener en cuenta que el tribunal contencioso-administrativo (en adelante VGH) Múnich prácticamente eliminó la sancionabilidad de la prohibición de salir del domicilio el 28.4.2020, cuando interpretó la disposición de tal forma que todo motivo no inadmisible a priori es idóneo para justificar la salida del hogar. La prohibición fue en gran parte neutralizada por el Senado y redactada nuevamente de acuerdo con el asunto, vid. VGH Múnich, decisión v. 28.44. 2020-20 NE 20.849, n. ${ }^{\circ}$ marg. 37 y ss. El § 5 BayinfSMV pertinente fue redactado de nuevo en base a una decisión de la VGH Múnich, decisión v. 30.3.2020-20 NE 20.632, por lo que al interpretarlo la VGH también podría referirse a las demás razones reconocidas por el que dictó el decreto. Después del 28.4.2020, difícilmente podría haber habido denuncias por dejar el domicilio sin motivo justificado, es por lo que las cifras reflejan la práctica de ejecución de un mes.

36 Sobre la posición y la estructura, vid. D. EHLERs, Die Verwaltungsgerichtliche Rechtskontrolle, en: Jura 2005, pp. 171-177; R. HERZOG, Verfassungsgerichtliche und verwaltungsgerichtliche Normenkontrolle, BayVBI. 1961, pp. 368-373. Para más información, consulte los comentarios sobre $§ 47$ VwGO.
} 
en Renania del Norte-Westfalia se introdujo el procedimiento el 1 de enero de 2019, lo que demuestra que este trámite no contaba como parte esencial garantía de protección de derecho. Ante la negación de una manifestación se invocaban las clásicas acciones de impugnación y dictar un acto administrativo. La protección legal contra medidas relativas a infracciones administrativas (avisos de multa) se dirigen a los tribunales ordinarios. Es probable que pronto se empiecen a resolver. En la práctica ganó terreno el control judicial administrativo de normas que originariamente era un procedimiento extraordinario, lo que ilustra la peculiaridad del sistema legal paralelo desde la perspectiva de la protección del derecho. Además, las protecciones del derecho de los tribunales administrativos siempre incluyen medidas cautelares. Se da la vuelta a la regla (el litigio principal decide el caso), porque prácticamente todo se resolvía con medidas cautelares (si el litigio no se ha resuelto, se seguirá aun tomando muchas decisiones sobre el asunto principal). En las medidas cautelares solo se realiza una prueba sumaria con una ponderación de las consecuencias. Los criterios de examen son principalmente las posibilidades de éxito de la solicitud de control de normas de la causa principal, siempre y cuando se pueda prever en el procedimiento de las medidas cautelares. A la hora de concretar los criterios de la pruebas erá importante el período de validez del decreto. Debido a que, para su aplicación o extinción al contrastar las desventajas de las medidas cautelares, la balanza se inclinará a favor del decreto con el «plazo de validez más corto». Cuanto más corto sea el plazo de validez restante, será menos probable que se requiera urgentemente una medida cautelar para evitar serias desventajas. En consecuencia, los procedimientos de control de normas de las medidas cautelares fracasan en el pronóstico las posibilidades de éxito en comparación con la amenaza de daño (generalmente muy breve). El fracaso a menudo no fue causado por una ponderación negativa de los bienes jurídicos fundamentales protegidos, sino principalmente por el elemento de tiempo. Algunos tribunales han entendido la regulación de los períodos de validez de corto plazo a modo de anticipo al autor del decreto: el autor del decreto pone con ello medidas sensibles con los derechos fundamentales que se impone a si mismo observar y mejorar: sin embargo, en la práctica, las medidas se han ampliado cada dos semanas. La naturaleza cortoplacista y el escaso conocimiento de los hechos sobre el desarrollo de la epidemia tuvieron un impacto en las medidas cautelares a favor del que otorgó el decreto. Esto explica por qué los decretos en principio no se derogaron ${ }^{37}$, lo que entretanto ha cambiado por completo ${ }^{38}$.

37 Por lo que se puede observar la primera derogación se refería a la prohibición de las excursiones del fin de semana de Pascua en Mecklemburgo-Pomerania Occidental, Tribunal Supremo Administrativo (en adelante OVG) Greifswald, resoluciones de 9.4.2020, 2 KM 268/20 OVG y 2 KM 281/20 OVG. La VGH Múnich no derogó los decretos, sino que las interpretó de manera restrictiva en varias ocasiones, ver su evidencia en nota al pie 27.

38 Una señal clara para una prueba de proporcionalidad intensificada, en la que el componente de tiempo ya no está a favor del decreto sino en perjuicio del decreto: OVG Münster, decisión de 29.6.2020-13 
Las demandas contra las prohibiciones de reunión tuvieron más probabilidades de éxito. Aquí, la medida cautelar conduce a un control más intenso que en el procedimiento de control de normas, porque el componente de tiempo juega a favor del solicitante. La libertad de reunión incluye el derecho del organizador a determinar el lugar y la hora de la reunión ${ }^{39}$. Ambos son esenciales para el propósito de la divulgación: uno se manifiesta dónde ocurre algo digno de crítica y dónde llega al destinatario correcto. Uno se manifiesta hoy y no dentro de dos semanas cuando se desvanezca la ocasión. Dado que el derecho fundamental a la libertad de reunión se concentra en el lugar y el tiempo, debe producirse la ponderación correspondientemente con la ley de protección de infecciones -en contraste con los derechos fundamentales cuya relevancia no está vinculada al aquí y ahora, pero que también puede posponerse si esto es adecuado para proteger otros bienes jurídicos. En el caso de la libertad de manifestación la medida cautelar no puede conducir a una reducción del control mediante prueba sumaria, porque debido al paso del tiempo casi siempre decide lo principal. Todo esto aumenta los requisitos de justificación de la prohibición de la reunión.

Por lo tanto, la práctica restrictiva de autorización de reuniones por parte de las autoridades fue corregida con relativa frecuencia, a veces con claras reprimendas. Las autoridades con frecuencia no cooperaron con el organizador sobre cómo respetar las reglas de distancia, aforo limitado y evitar peligros innecesarios. Como medida preventiva general fueron rechazados también pequeños eventos con participantes con menos dedos dígitos y con conceptos de higiene adecuados. En ocasiones el rechazo se basaba en el riesgo general de infección para los transeúntes, los contramanifestantes y las fuerzas de seguridad. Por lo tanto, el organizador fue responsabilizado del comportamiento de terceros (no adaptable a su concepto de higiene) o de los riesgos que ya conllevabala profesión de policía ${ }^{40}$. Como en base al derecho a la libertad de reunión no eran razones admisibles para su denegación, las decisiones de los tribunales administrativos en bastantes casos (pero de ninguna manera en todos) se tomaron a favor de la libertad de reunión ${ }^{41}$.

En este contexto, la decisión del tribunal contencioso-administrativo VGH Mannheimes digna de mención, porque formuló los riesgos de infección aceptables $^{42}$. Aquí, se hizo una ponderación expresa entre los bienes jurídicos de la salud y la libertad de manifestación. Durante aquellos meses raramente

B 940/20.NE - Lockdown Gütersloh. La OVG derogó el decreto un día antes del vencimiento de su período de vigencia.

39 Vid. únicamente H. D. Jarass, en: Jarass/Pieroth, Grundgesetz Kommentar, 16 edición, 2020, Art. 8, n. ${ }^{\circ}$ marg. 5 .

40 Los hechos correspondientes son comunicados por el Tribunal Constitucional Federal (en adelante BVerfG), 1 ra Cámara del 1er Senado, decisión de 15.4.2020-1 BvR 828/20; VG Münster, decisión de 25.4.2020, 5 L 361/20.

41 Ejemplos: VG Münster, decisión de 25.4.2020, 5 L 361/20 - Transporte de residuos atómicos; Münster; VGH Mannheim, decisión de 23.5.2020-1 S 1586/20 MD Reunión de AFD en Stuttgart.

42 Vid. Pie de página 33. 
se encontraron declaraciones sobre los riesgos aceptables frente al contagio con COVID-19.

Por otro lado, la aportación de la jurisprudencia del TCF fue bastante débil. Su contribución a asegurar las libertades fundamentales durante la pandemia del coronavirus ha sido bastante marginal. Destacan únicamente resoluciones puntuales sobre la libertad de reunión $\mathrm{n}^{43}$ y de religión ${ }^{44}$. Al fin y al cabo, se mantuvieron las garantías mínimas de los derechos fundamentales. Es decir, que las prohibiciones generales del culto son inadmisibles y excepcionalmente también deben permitirse las reuniones. En este contexto no se decidió nada espectacular. En la gran mayoría de los casos, sin embargo, los solicitantes no tuvieron éxito. La mayoría de las veces, la solicitud urgente fue inadmitida, porque el proceso judicial administrativo no se había llevado a cabo o la alegación no estaba justifi$\mathrm{cada}^{45}$. En la jurisprudencia de Karlsruhe también es problemático el uso de la evaluación de riesgos del Instituto Robert $\mathrm{Koch}^{46}$. Dado que otros podereshacían referencia al Instituto Robert Koch de manera estándar, y también la Canciller declaró seguir las directrices del RKI, esta estimación de riesgo tuvo tal fuerza prejudicial que neutralizó el contenido de control del tercer poder, porque todos constantemente hacían referencia a las mismas estimaciones.

Además, puertas afuera la jurisprudencia de cámara del primer senado generó la impresión de no tener objeciones desde el punto de vista constitucional (que no tiene en cuenta ni las medidas cautelares, ni los criterios de admisibilidad).El problema fundamental — la ausencia de ponderación — fue abordado en las

43 Exitosa solicitud urgente contra la prohibición de la libertad de manifestación por parte de la ciudad de Gießen: BVerfG, 1. Cámara del Primer Senado, decisión de 15.4.2020-1 BvR 828/20; Solicitud urgente exitosa contra la prohibición de manifestación por parte de la ciudad de Stuttgart: BVerfG, 1. Cámara del Primer Senado, decisión de 17. 4.2020-1 BvQ 37/20. Ningún éxito, ya que se esperaba un grupo considerablemente mayor de participantes: BVerfG, 1. Cámara del Primer Senado, decisión de 1.5.2020-1 BvR 1003/20.

44 Solicitud urgente infructuosa contra la prohibición de la Misa de Pascua por parte de la Segunda Cámara del Primer Senado, decisión de 10.4.2020-1 BvQ 28/20. Allí, sin embargo, se solicita un examen riguroso continuo de la proporcionalidad basado en los conocimientos actuales. Solicitud urgente exitosa contra la prohibición general de los servicios religiosos en el decreto sobre el coronavirus, porque esto significa que las decisiones excepcionales no son posibles: 2. Cámara del Primer Senado, decisión de 29.04.2020-1 BvQ 44/20.

45 Solicitudes urgentes inadmisibles: BVerfG, 1. Cámara del Primer Senado, decisión de 20.3.2020-1 BvR 661/20; Sentencia de 31.3.2020-1 BvR 712/20; Sentencia de 9.4.2020-1 BvQ 27/20; Sentencia de 9.4.2020-1 BvQ 29/20; Sentencia de 10.4. 2020-1 BvQ 26/20; Sentencia de 24.4.2020, 1 BvR 900/20; 2. Cámara del Primer Senado, sentencia de 18.4.2020-1 BvR 829/20; Sentencia de 9.6.2020-1 BvR 1230/20; 3. Cámara del Primer Senado, Sentencia de 12. 5.2020-1 BvR 1027/20.

46 Refiriéndose en detalle a la experiencia de la RKI destacan por ejemplo BVerfG, 2. cámara del primer senado, Sentencia de 10.4.2020-1 BvQ 28/20 n. ${ }^{\circ}$ marg. 14 sobre la prohibición del culto en Pascua, especialmente para los católicos, para quienes la asistencia a misa es un deber religioso. Ningún éxito para el solicitante cuya terapia de depresión no pudo llevarse a cabo: BVerfG, 1. cámara del primer Senado, sentencia de 5.1.2020 - 1 BvQ 42/20. No me queda claro por qué las excepciones en casos individuales conllevarían riesgo de colapso del sistema de salud. Similar a la BVerfG, 1. cámara del primer senado, sentencia de 16.5.2020-1 BvQ 55/20, n. ${ }^{\circ}$ marg. 14: Los números reducidos a nivel local no «cuestionan radicalmente» el riesgo de infección. 
resoluciones en muy raras ocasiones. En relación al silencio sobre este asunto la primera cámara del primer senado, envió una señal a las autoridades de ejecución y los juzgados de primera instancia. Sobre la intensidad de control por parte del TCF al legislador en relación a los decretos se vió poco (justificaciones en el proceso legislativo, verificación de hechos como requisito previo para la viabilidad del test de proporcionalidad).

Tampoco aquí tuvieron ninguna utilidad los criterios que de otro modo se aplican en situaciones en las que los intereses de la seguridad colectiva colisionan con los intereses de libertad, como la legislación moderna de seguridad ${ }^{47}$ : por ejemplo, en el aumento requisitos específicos más estrictos en vista de la intensidad de la injerencia, odispersión y los efectos disuasorios sobre el comportamiento social. Por supuesto, todo ello es consecuencia de la constelación procesal (medidas cautelares en la mayoría de solicitudes inadmisiblesformalmente). Sin embargo, no debería haber sido necesario eliminar frases centrales de las resoluciones, por ejemplo, a la hora de evaluar las posibilidades de éxito la formulación repetida de la ponderación de los bienes jurídicos de la vida y la salud, no llevaban a la emisión una orden provisional de acuerdo con $\$ 32$ BVerfGG. Con tales formulaciones el TCF no contribuyó a esclarecer cuestiones relativas a los bienes jurídicos protegidos y conseguir el fin perseguido. Más bien dio la impresión de que la vida y la salud eran bienes jurídicos más importantes que las libertades fundamentales (Freibeitsrechte), lo que en este nivel de abstracción no es cierto. Las resoluciones sobre la libertad de reunión y la prohibición de los servicios de culto siguieron cumpliéndose, pero en general no que se probaramás la proporcionalidad de la política del coronavirus o que se institucionalizara la búsqueda de medidas más suaves.

En mi opinión, el mérito de haber provocado un cambio fundamental en la cultura de la toma de decisiones se debe al Tribunal Supremo Administrativo $(\mathrm{OVG})$ de Münster ${ }^{48}$. Lasentencia de Gütersloh señala el camino de regreso a la prueba ordinaria de proporcionalidad, en la que no existen privilegio temporales para la medida, porque es posible tener una base sobre los hechos mucho más precisa. Como consecuencia son posibles también las pruebas de necesidad y adecuación, especialmente porque el objetivo de la medida (basada en los derechos de capacidad de control del curso de la pandemia, evitar la demanda excesivade la unidad de cuidados intensivos) se puede cumplir por otros medios más allá de la medida en cuestión.

47 Vid. BVerfGE 113, 348 (375-378) [2005] - vigilancia telefónica preventiva: ley demasiado indefinida; 120, 274 (315-318) [2008] - Investigación on-line: falta de claridad de las normas; 120.378 (407 y ss.) [2008] - Registro de matrículas: propósito poco claro; 141, 220 (265) [2016] - Ley BKA: Se critica la claridad de las normas y la certeza; BVerfGE 150, 244 (279) [2018] control de matrículas de Baviera: certeza violada; BVerfG, sentencia de 19.5.2020, 1 BvR 2835/17-Vigilancia de telecomunicaciones en el extranjero II, n. ${ }^{\circ}$ marg. 137: aumento de los requisitos específicos para el secreto y la difusión.

48 OVG Münster, sentencia de 29. 6. 2020-13 B 940/20.NE-Lockclown Gütersloh. 
En las sentencias delos tribunales constitucionales de los Länder solo hacen referencia a dos valoraciones contrapuestas sobre la proporcionalidad ${ }^{49}$. En este punto no puedo entrar a tratarla problemática de la igualdad, que ocupó a muchos tribunales en relación a la apertura de escuelas y tiendas (criterio de $800 \mathrm{~m} 2$ ). Estas decisiones no aportan gran cosa a nuestro tema, porque comprueban la coherencia sistemática de la medida dentro de la cultura de la prohibición. Es decir, libertades ganadas con las aperturas se tematizan como diferenciaciones contrarias a la igualdad. En casos aislados esto podría tener un efecto a favor o en contra de nuevas aperturas. En general, los tribunales administrativos y constitucionales rara vez se pronunciaron a favor de la protección de los derechos fundamentales, lo que a nivel político se interpreto como una confirmación. En los gobiernos circularon listas de decisiones judiciales, que incluían decisiones a favor y en contra, pero sin analizarlos argumentos de ponderación de manera diferenciada. Así, algunas sentencias provisionalmente favorables a los decretos sobre el coronavirus, contenían restricciones en la materia o enfatizaban el componente de tiempo tan central en la prueba de proporcionalidad (medida «actualmente» proporcional). Los jefes de gobierno tuvieron mucho menos en cuenta estas diferencias que los departamentos ministeriales especializados. El control jurisdiccional fue debilitado en múltiples ocasiones: por un lado, por el procedimiento de las medidas cautelares, en el que sólo se realiza un control sumario. Por otro lado, por la débilbase de antecedentes de hechode pronóstico de peligros (nuevo virus), lo que debilita de forma decisiva el control de proporcionalidad. El ejecutivo se beneficia políticamente de la recuperación del control sobre las normas generales-abstractas, aunque estas tienen un efecto específico a nivel individual. La estructura de control ordinario se ha desplazado al sistema legal paralelo.

\section{Nuevamente: ciudadanos y federalismo}

En definitiva, en términos de efectividad de la protección de los derechos fundamentales en la conciencia pública destacaron dos de los factores arriba mencionados. Por un lado, la ciudadanía se expresó en la defensa de los derechos civiles. En numerosas manifestaciones se protestó en contra de injerencias a las libertades. Estas manifestaciones tuvieron una gran repercusión en el debate público, porque por primera se volvió a centrar la atención en el problema de las libertades, que hasta entonces no había recibido suficiente atención en los órganos estatales, siendo solo un tema secundario en el acompañamiento mediático a la política coronavirus.

49 Confirmando BayVerfGH, sentencia de 26.3.2020 - Vf. 6-VII-20; sentencia de 24.4.2020 - Vf. 29-VII-20; sentencia de 8.5.2020 - Vf. 34-VII-20; derogando VerfGH Saarland, decisión de 28.4.2020 - Lv $7 / 20$. 
También el federalismo contribuyó de forma efectiva en la protección de los derechos fundamentales. Gracias a las competencias recaídas en los 16 gobiernos regionales surgió por propia inercia una competencia normativa material, que no debe ser valorada como una sobreoferta o subdemanda de competencias, sino como una competencia de la medida más efectiva y suave. Nuestro federalismo, a diferencia de otros Estados, creó un debate público permanente sobre el objetivo y la dirección de las medidas, que también fue impulsado por el interés político de los presidentes de los Länder de destacar en el escenario político federal. Sin embargo, en el federalismo este interés político sobre el conjunto del Estado tiene un efecto sensible a los derechos fundamentales. Se presentan alternativas con las que se aumenta la presión de justificación de las medidas.

No se debe de subestimar el efecto federativo de las medidas más suaves y el cambio de medidas abstractas generales a medidas concretas locales. El argumento de los presidentes de los Länder de que solo tenían un nivel de contagio muy bajo, - en especial en los nuevos Estados federales_-, ante el cual ya no se debería reaccionar de forma abstracta y general, no podría contradecirse desde la perspectiva de la protección de la salud.

Un argumento de este tipo solo puede ser serio si existen áreas de competencias no centralizadas. En contraste con esta política, estaba la actitud del gobierno federal, que no tenía competencia en la materia (a excepción del Ministro de salud autorizado para dictar decretos especiales) y que en consecuencia solo podía asumir el papel moderador. Esto, sin embargo, solo se justificaba con la preocupación de evitar un «mosaico». En general, esto significa: con el federalismo se gana libertad en la totalidad del Estado a través del pluralismo de competencias. Si el gobierno federal actuara en su lugar, las decisiones serían más invasivas de lo que requeriría el peligro concreto (que solo puede ser determinado localmente).

\section{ABOLICIÓN DEL SISTEMA LEGAL PARALELO}

Ahora nos enfrentamos ante la tarea de acabar con el sistema legal paralelo originado por la pandemia del coronavirus. Varias señales indican que ya estamos en camino. Se ha sobrepasado la capacidad de los decretos para combatir la pandemia. La reivindicación del Gobierno Bávaro anteriormente citada «de regular la vida pública y privada mediante decretos legislativos, disposiciones generales y las notificaciones» desde un punto de vista técnico normativo derivaba en lo absurdo. Sin cesar fue necesario promulgar decretos cada vez más específicos. Se comprobaba la compatibilidad de los comportamientos cada vez más específicos con los decretos. Los pronunciamientos en Internet, que eran cada vez eran más largos, tenían como finalidad combatir las incertidumbres legales. Las preguntas frecuentes aclaraban consultas como si el cambio de neumáticos de invierno justificaba la salida de la vivienda. Se utilizaron listas para regular que las prohibiciones de negocios no incluyeran tiendas de necesidades para mascotas o si las 
tiendas de bicicletas sin un taller de reparación de bicicletas se mantenían abiertas o no. Este derecho basado en decretos no solo restringe las libertades fundamentales en todos los ámbitos, sino que incapacita a los ciudadanos y la sociedad de perseguir el objetivo de la protección contra infecciones de forma autosuficiente. No se confía en su propia evaluación los riesgos, porque el riesgo para uno mismo, que es parte del riesgo de vida general, siempre puede incluir un riesgo para otros (infección por personas infectadas no reconocidas). Sin embargo, el ejecutivo asume la tarea de definir los riesgos admisibles: desde comprar suministros para mascotas hasta cambiar llantas. Digamos que en Baden-Württemberg un decreto regulala prohibición de nadar, así como la entrada y salida en la piscina ${ }^{50}$ mediante la circulación en un solo sentido de los carriles separados en las piscinas de $50 \mathrm{~m}$. Otro decreto regula la comida y bebida durante el transporte en autocares $^{51}$. Se podrían agregar muchos otros ejemplos de otros Länder. Con tal nivel normativo se crea una locura normativa, inevitable en un Estado de derecho. Sobre todo, cuando se valora la protección de la vida y la salud de forma absoluta, no se reconocen riesgos tolerables, y no se admite el peligro personal como un riesgo general de la vida.

Teniendo en cuenta que la severidad la justificación frente al test de proporcionalidad ante las infracciones de los derechos fundamentales es cada vez más exigente, debido al el factor de paso del tiempo y el aumento de los hechos, la técnica de proporcionalidad nos conduce directamente a Schilda ${ }^{52}$. Por tanto, el siguiente paso a seguir deberá de ser la conversión a reglas de conducta, subsumibles a la situación individual. En vista de la cada vez mayor experiencia del curso de la infección y su concentración en los brotes locales, mediante una regulación con decretos generales-abstractos se pierde el objetivo de conseguir una protección eficaz de la salud.

En consecuencia, la responsabilidad se desplaza cada vez más del gobierno regional a las autoridades locales (como autoridades sanitarias de los municipios y distritos). Allí es posible reaccionar de manera más efectiva y proporcional, porque

$50 \S 2$ No. 1 a), No. 2 Decreto del Ministerio de Cultura y el Ministerio de Asuntos Sociales de Baden-Württemberg sobre baños y saunas (Decreto sobre Corona Baños y Saunas) de 25.6.2020, vigente desde el 1.7.2020.

$51 \S 7$ del decreto del Ministerio de Transporte y del Ministerio de Asuntos Sociales de Baden-Württemberg para contener la transmisión del virus corona en los autocares (Decreto corona sobre autocares) de 25.6. 2020, vigente desde el 1.7.2020.

52 La leyenda de Schilda todavía forma parte de la cultura de habla alemana y se ha abierto camino en el vocabulario alemán. Los Schildbürger, que viven en la ciudad ficticia de Schilda, son los principales protagonistas de toda una serie de cuentos. Los ciudadanos de Schilda eran generalmente conocidos por ser extremadamente inteligentes, por lo que eran consejeros muy solicitados de los reyes y emperadores. Dado que el lugar se iba despoblando cambiaron de estrategia para lograr que sus ciudadanos se quedaran en el pueblo. La ciudadanía comenzó a reemplazar gradualmente su inteligencia por la tontería. Tuvieron tanto éxito que con el tiempo se mantuvieron su insensatez y se hicieron muy conocidos por ello. El término Schildbürgerstreich se usa en el lenguaje cotidiano para referirse a regulaciones locas y engañosas o excesos de burocracia (Nota del Traductor). 
las medidas se basan en hechos de casos individuales y no por cálculos del modelo virológico. Y porque el aspecto de garantía de la libertad de ejecución individual es efectivo. En este contexto, las medidas contra la propagación de la infección en la fábrica de carne de Tönnies en el distrito de Gütersloh con la reacción judicial del Tribunal Supremo Administrativo (OVG)de Münster fue un ejemplo instructivo. A mediados de julio de 2020existía ya un consenso político de que no se llegaría a un segundo confinamiento incluso si la tasa de infección estallar en invierno, y que se respondería puntual y regionalmente de forma selectiva ${ }^{53}$.

Por tanto, las especificaciones políticas van en la dirección de reducir el orden jurídico paralelo. Lo que desde la perspectiva de los derechos fundamentales es bienvenido. A medio plazo, naturalmente, surge la pregunta de cuándo se incluirá el riesgo de enfermedad COVID-19 entre los riesgos de la vida general. Como muy tarde para entonces no habrá justificación para la existencia de medidas que propician un sistema legal paralelo. Por el momento, sin embargo, nadie parece querer formular las condiciones políticas bajo las cuales se podría hacer tal declaración. ¿Quién podría siquiera hacer tal declaración? ¿La OMS o la RKI? ¿Qué presidente quiere asumir la responsabilidad política de tal declaración? En última instancia, tales declaraciones solo pueden ser respondidos por los órganos representativos, cuyas tareas incluyen configuración y armonización los derechos fundamentales. Los riesgos asumibles deben decidirse mediante una división del trabajo entre el establecimiento de normas generales y abstractas (por ejemplo, el permiso al tráfico de vehículos de motor) y la estimación de riesgos concretos individuales que conllevan un peligro personal. Los decretos gubernamentales no presentan un valor cualitativo extra. La «hora del ejecutivo» da la hora, pero no la detiene.

También muestra lo adecuadas que son las categorías de pensamiento de los derechos fundamentales para reaccionar a peligros desconocidos y nuevas situaciones. Al fin y al cabo, los derechos fundamentales piden tres cosas a los que deciden sobre ellos: (l) Determinar con precisión el objetivo de la acción (por ejemplo, dirección de la pandemia basada en su curso) y retóricamente no basarse en suposiciones («Se trata de vida o muerte»).(2) Tratar las preocupaciones relevantes en su amplitud y no refugiarse en el discurso experto del personal especializado, que en general desatiende sistemáticamente la protección los derechos fundamentales.(3) Buscar continuamente medios más suaves, lo que significa, por un lado, procesar los hechos inmediatamente (referencia de tiempo y de lugar) $y$, por otro lado, no atribuir a los peligros reglas de causalidades primitivas (equivalencia), sino considerar la doctrina normativa contable correctiva.

En este sentido, los derechos fundamentales no solo sirven para garantizar los derechos individuales de libertad. No solo justifican la valía del ordenamiento

53 Vid. El convenio federal-estatal de 16.7.2020 «Luchar contra los brotes locales de forma selectiva», https://www.bundesregierung.de/resource/b lob / ... 
jurídico, sino que también formulan el programa de toma de decisiones de una filosofía política éticamente responsable.

$* * *$

TITLE: Protection of fundamental rights in the coronavirus pandemic

AвSTRACT: Has the situation of fundamental rights changed in times of the corona pandemic? One thing is certain: the protection of basic rights is not a one-way street that begins with the individual, but a promise of the Basic Law that must be implemented by all state powers. The legal system as such, not just the legal status of the individual, should be a free one. In the last few months, even the case law of the lower courts and the Federal Constitutional Court has proven to be rather pale. The merit of having brought about a fundamental change in the executive decision-making culture within the judiciary belongs in the perception of the author to the Supreme Administrative Court (OVG) Münster, which in its "Güterslob decision» (OVG Münster, decision of 29.06.2020 - 13 B 940 / 20.NE - Lockdown Güterslob) showed the way back to a normal proportionality test.

RESUMEN: ¿Ha cambiado la situación de los derechos fundamentales en tiempos de la pandemia provocada por el coronavirus? Lo cierto es que la protección de los derechos fundamentales no es una vía de un solo sentido que comienza con el individuo, sino una promesa de la Ley Fundamental que debe ser implementada por todos los poderes estatales. Todo el ordenamiento jurídico en si debe ser libre, no solo el estatus legal del individuo. En los últimos meses, incluso la jurisprudencia de los tribunales inferiores y del Tribunal Constitucional Federal ha demostrado ser bastante débil. En opinión del autor, el mérito de haber provocado un cambio fundamental en la cultura de ejecución de toma de decisiones dentro del poder judicial corresponde al Tribunal Supremo Administrativo (en adelante OVG) de Münster, que en su "decisión Güterslob» (OVG Münster, decisión de 29.06.2020-13 B 940/20.NE-Lockdown Güterslob) volvió a la aplicación correcta de la prueba de proporcionalidad.

KEY WORDS: Basic Law, principle of proportionality, Infection Protection Act, medidas cautelares, coronavirus, decree, Fundamental Right.

PalabRas Clave: Ley Fundamental, principio de proporcionalidad, Ley de protección contra infecciones, coronavirus, decreto, derecho fundamental.

FECHA DE RECEPCIÓN: 03.11.2020

FECHA DE ACEPTACIÓN: 26.01.2021

UNED. Teoría y Realidad Constitucional, núm. 47, 2021, ISSN 1139-5583, pp. 71-96 